\title{
Infrastructure: We must find alternatives to state funding
}

Written by: Ibrahim Assane Mayaki, Chief Executive Officer (CEO), New Partnership for Africa's Development (NEPAD)

Last update: 28 January 2020

On 16 October 2018, the authorities of the Democratic Republic of Congo (DRC) announced the signing of an Inga 3 project exclusive development agreement with two consortia (Chinese and Spanish). This is a milestone for Africa. After eight years of studies and discussions, this hydroelectric dam project on the Congo River will finally enter its operational phase.

Inga 3 is a project designed to lead to an extra production of 11,000 megawatts (MW) of clean renewable, permanently available energy that will benefit the entire power grid in the region. The benefits of this project will be felt as far as South Africa. The China Inga 3, a consortium including Chinese and European companies, plans to invest $\$ 14$ billion. If all goes well, Inga 3 will be the largest hydroelectric project ever built on the continent. It will also showcase opportunities offered by public partnerships for infrastructure development in Africa, as well as regional integration.

Infrastructure deficit is one of the most serious problems our continent faces. It is most obvious in the energy sector. Although 145 million people on the African continent have been able to connect to electricity since the beginning of the millennium, 645 million Africans are still deprived of it. How can we expect to start a virtuous circle of industrialisation if the most basic prerequisite-access to affordable energy-is not fulfilled?

We estimate that the annual investment threshold for Africa's infrastructure deficit is $\$ 120$ billion. As of now, annual investment stands at about only $\$ 50$ billion. The continent now devotes a little more than $4 \%$ of its GDP to infrastructure equipment. This is better than ten years ago when it dropped to $2 \%$. But it is still less than in China, where this proportion is up to $14 \%$. There are also major differences between countries and the structure of their economies, depending on their exposure to commodity prices in particular.

This lack of infrastructure carries big costs. When economies are isolated, they become less attractive, since unified markets on a regional scale are difficult to 
create. Inadequate infrastructure increases production costs, weighs on business's competitiveness and negatively impacts foreign direct investment. Still, Africa must create 450 million jobs over the next twenty years to absorb its population growth. World Bank studies have shown that infrastructure deficit costs the continent 2 points of annual growth and generates a $40 \%$ shortfall in competitiveness gains for its enterprises.

Having stated the fact, we need to think about solutions. Be it in energy or communication corridors, the regional dimension is essential and must receive the greatest attention. Infrastructure covering several countries in the same region is more attractive to investors (both public and private) because it allows the pooling of costs and promotes integration. In 2012, the African Union set up an African Infrastructure Development Program (PIDA) managed jointly by the NEPAD Agency and the African Development Bank (AfDB). Its roadmap focuses on structuring cross-border projects, numbering 51 programmes which are broken down into 433 individual projects spanning; ICT, Energy, Water and Transportation projects, for a total package of $\$ 360$ billion. They are the pivot of the continent's real economic takeoff.

The approach chosen by PIDA is highly original in that it anchors the projects exclusively in public-private partnerships (PPP). Indeed, the real question is not whether to invest more, but rather, who should invest more? Again we say, "Africa must first rely on its own means and resources to carry out its development." But is this true in the infrastructure domain? The answer is "yes," but with some reservations. Investment in infrastructure is an absolute necessity, but it must not be to the detriment of other equally important programmes such as investment in education, health or agriculture. Therefore, association with the private sector on the one hand, and international co-operation on the other hand, are credible alternatives to state funding. This is the solution that, as the NEPAD Agency, we never stop recommending, and this is the solution DRC authorities have chosen to adopt with the Inga 3 project.

Therefore, the key issue lies in private sector participation in the major PIDA projects, in the promotion of requisite regional integration. In this regard, the NEPAD Agency launched the " $5 \%$ Agenda" in 2017. This campaign aims to raise awareness and mobilise the African financial sector and encourage African insurance companies and pension funds to invest at least $5 \%$ of their investment portfolio to infrastructure. Currently the allocation is only $1.5 \%$. The growth margins are considerable because the amount of assets under management held by African pension funds, insurance companies, and institutional investors stands at \$1.1 trillion. In addition to its exemplary nature, the " $5 \%$ Agenda" realisation will act as a positive signal; not only will it reduce the perception of risk on the continent, it will also leverage the private sector and international partners' participation in the financing of major African infrastructure. These are more than likely to spur regional integration. 
Visit www.nepad.org/

COECD Observer October 2018 